\title{
Experimental Investigation of Heat and Mass Transfer in Tubular Membrane Distillation Module for Desalination
}

\author{
Adnan Al-Hathal Al-Anezi, ${ }^{1}$ Adel O. Sharif, ${ }^{1}$ M. I. Sanduk, ${ }^{1}$ and A. R. Khan ${ }^{2}$ \\ ${ }^{1}$ Centre for Osmosis Research and Applications (CORA), Chemical and Process Engineering Department, Faculty of Engineering and \\ Physical Sciences, University of Surrey, Guildford GU2 7XH, UK \\ ${ }^{2}$ Department of Environment Technology and Management, College for Women, Kuwait University, P.O. Box 5969, Safat 13060, Kuwait \\ Correspondence should be addressed to Adnan Al-Hathal Al-Anezi, AdnanAlHathal@yahoo.com
}

Received 24 December 2011; Accepted 9 February 2012

Academic Editors: P. Fievet and A. M. Seayad

Copyright (C) 2012 Adnan Al-Hathal Al-Anezi et al. This is an open access article distributed under the Creative Commons Attribution License, which permits unrestricted use, distribution, and reproduction in any medium, provided the original work is properly cited.

\begin{abstract}
Membrane distillation is a thermally driven membrane process for seawater desalination and purification at moderate temperatures and pressures. A hydrophobic micro-porous membrane is used in this process, which separates hot and cold water, allowing water vapor to pass through; while restricting the movement of liquid water, due to its hydrophobic nature. This paper provides an experimental investigation of heat and mass transfer in tubular membrane module for water desalination. Different operating parameters have been examined to determine the mass transport mechanism of water vapor. Based on the experimental results, the effects of operating parameters on permeate flux and the heat transfer analysis have been presented and discussed in details.
\end{abstract}

\section{Introduction}

Membrane distillation (MD) is a relatively new thermal membrane separation process in which a microporous hydrophobic membrane separates water vapor from a liquid aqueous solution by transport through hydrophobic membrane pores, where the driving force is the vapor pressure difference created by temperature difference across the hydrophobic membrane. The separation mechanism of membrane distillation is based on the principle of vaporliquid equilibrium [1-3].

Membrane distillation (MD) is attracting increasing desalination research interest because of its low cost. This option saves energy over conventional desalination processes [4]. Importantly, this is considered by most researchers to be a better alternative to traditional desalination processes such as reverse osmosis (RO), multistage flash distillation (MSF), electrodialysis (ED), and so forth. MD produces ultrapure water without high temperatures or high pressures [2].

The aims of this experimental work are to elucidate the mechanism of heat and mass transfers of the MD process, to study the effect of process parameters on permeate flux and to investigate in details the heat transfer process and temperature polarization using a heat-mass transfer analogy.

\section{Transport Process}

Membrane distillation (MD) is a simultaneous process which involves both heat and mass transfer processes. In MD water vapor, molecules transfer from the warm feed side to the condensation sides. Since both processes are involved the heat and mass transfer profiles are depicted as shown in Figure 1.

2.1. Mass Transfer. The mass transfer of water in MD process generally consists of two steps: the first occurs through the boundary layer at the feed side, and the second occurs across the membrane itself. Mass transfer across the membrane is somewhat complicated and includes several basic mechanisms. There are two approaches for modeling MD. The first one concerns the modeling of the transport mechanism through the hydrophobic membrane. The second concerns with the overall modeling for predicting the permeate flux at given operation conditions [5]. A linear relationship between 


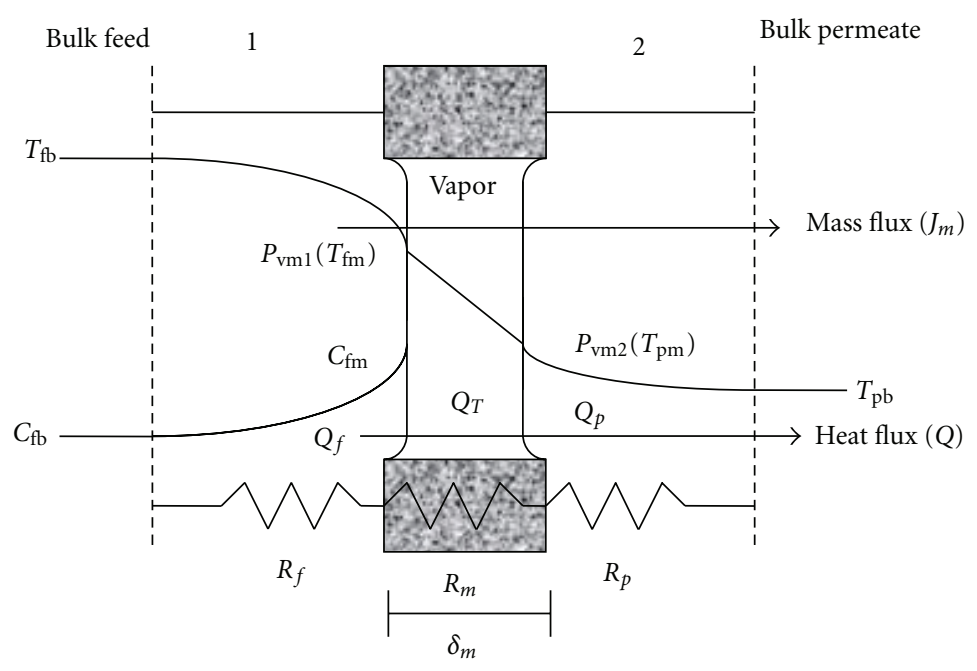

Figure 1: Heat and mass transfer profiles in membrane distillation.

the mass flux $\left(J_{m}\right)$ and the water vapor pressure difference $\Delta P_{v}$ across the membrane was suggested to describe the water vapor transport in $\mathrm{MD}$ and the basic equation is given by the general expressions $[1,2,6]$ :

$$
J_{m}=C_{m} \Delta P_{v}=\frac{k_{f} M_{w}}{R T_{m}}\left(P_{v m 1}-P_{v m 2}\right),
$$

where $J_{m}$ is the water vapor mass flux, $C_{m}$ is the membrane distillation coefficient and can be a function of pressure, temperature, and the composition within the membrane as well depends on the membrane structure (porosity $(\varepsilon)$, thickness $\left(\delta_{m}\right)$, pore size diameter $\left.\left(d_{p}\right)\right), k_{f}$ is the mass transfer coefficient, and $P_{v m 1}$ and $P_{v m 2}$ are the vapor pressures of water vapor evaluated at the membrane surface temperatures $T_{f m}$ and $T_{p m}$. The differences between bulk feed temperatures $T_{f b}$ and $T_{f m}$ and between bulk permeate temperatures $T_{p b}$ and $T_{p m}$ signify the temperature polarization coefficient. The mass transfer coefficient $C_{m}$ can be determined experimentally or theoretically $[6,7]$. For pure liquid, the water vapor pressure at liquid-vapor interface can be calculated using the Antoine equation $[2,6]$ :

$$
P_{v}=\exp \left(23.1964-\frac{3816.44}{T_{m}-46.13}\right)
$$

2.2. Heat Transfer. The heat transfer in MD process can be summarized in three steps.

(i) Convection from the feed bulk to the vapor-liquid interface at the membrane surface (i.e., the thermal boundary layer at the feed side)

$$
Q_{f}=h_{f}\left(T_{f}-T_{f m}\right),
$$

where $Q_{f}\left(\mathrm{~W} / \mathrm{m}^{2}\right)$ and $h_{f}\left(\mathrm{~W} / \mathrm{m}^{2} \mathrm{~K}\right)$ are the heat flux and heat transfer coefficients at feed side, respectively. (ii) Evaporation and conduction through the microporous membrane, where the heat flux can be written as

$$
\begin{gathered}
Q_{v}=J_{m} \Delta H_{v}, \\
Q_{c}=\frac{k_{m}}{\delta_{m}}\left(T_{f m}-T_{p m}\right) .
\end{gathered}
$$

(iii) Convection from the vapor-liquid interface at the membrane surface to the permeate side (i.e., the thermal boundary layer of the permeate side) $[6,8-$ 10]:

$$
Q_{p}=h_{p}\left(T_{p m}-T_{p}\right),
$$

where $Q_{p}\left(\mathrm{~W} / \mathrm{m}^{2}\right)$ and $h_{p}\left(\mathrm{~W} / \mathrm{m}^{2} \mathrm{~K}\right)$ are the heat flux and heat transfer coefficients at permeate side, respectively.

The total heat flux $\left(Q_{T}\right)$, across the membrane, is expressed by the following equation:

$$
\begin{aligned}
Q_{T} & =U \Delta T_{b} \\
& =\left[\frac{1}{h_{f}}+\frac{1}{h_{m}+\left(J_{m} \Delta H_{v}\right) /\left(T_{f m}-T_{p m}\right)}+\frac{1}{h_{p}}\right]^{-1} \Delta T_{b} \\
& =Q_{v}+Q_{c},
\end{aligned}
$$

where $U$ is the overall heat transfer coefficient, $\Delta T_{b}$ is bulk temperature difference among the feed and permeate sides, $\Delta H_{v}$ is the latent heat of vaporization, respectively.

Under steady state conditions, derived from the heat balance, the heat transfer in the individual compartments of system is represented by the following equation:

$$
\begin{aligned}
Q & =h_{f}\left(T_{f}-T_{f m}\right) \\
& =h_{m}\left(T_{f m}-T_{p m}\right)+J_{m} \Delta H_{v}=h_{p}\left(T_{p m}-T_{p}\right) .
\end{aligned}
$$




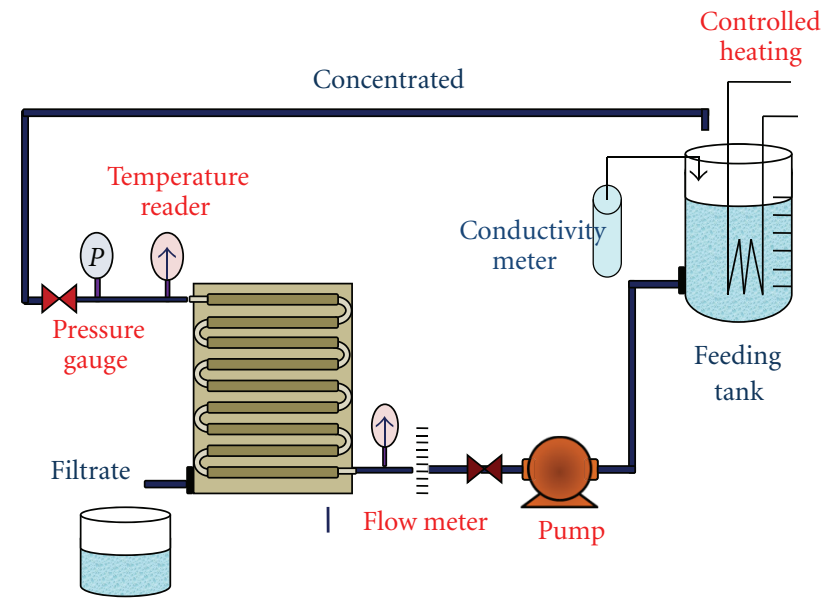

FIGURE 2: Experimental setup.

On the basis of (7), the membrane surface temperatures $T_{f m}$ and $T_{p m}$ on both sides of the membrane can be estimated using the following equations:

$$
\begin{aligned}
T_{f m} & =\frac{h_{m}\left(T_{p}+\left(h_{f} / h_{p}\right) T_{f}\right)+h_{f} T_{f}-J_{m} \Delta H_{v}}{h_{m}+h_{f}\left(1+h_{m} / h_{p}\right)}, \\
T_{p m} & =\frac{h_{m}\left(T_{f}+\left(h_{p} / h_{f}\right) T_{p}\right)+h_{p} T_{p}+J_{m} \Delta H_{v}}{h_{m}+h_{p}\left(1+h_{m} / h_{f}\right)} .
\end{aligned}
$$

Further the heat transfer coefficient of the membrane $h_{m}$ can be determined on the basis of thermal conductivities of the membrane $k_{s}$ and of the vapor that fills the pores $k_{g}$, using the following equation:

$$
h_{m}=\frac{k_{m}}{\delta_{m}}=\varepsilon \cdot k_{s}+\frac{(1-\varepsilon) k_{g}}{\delta_{m}} .
$$

The heat transfer coefficients of the boundary layers $h_{f}$ and $h_{p}$ can be estimated experimentally or can be calculated using empirical correlations of dimensionless groups, namely, Nusselt number ( $\mathrm{Nu})$, Reynolds number ( $\mathrm{Re})$, and Prandtl number $(\mathrm{Pr})$. These numbers can be calculated directly from the data available for aqueous $\mathrm{NaCl}$ solutions and water, using (5) [11-13]:

$$
\mathrm{Nu}=a \operatorname{Re}^{b} \operatorname{Pr}^{c},
$$

where $a, b$, and $c$ are correlation coefficients dependent upon specific hydrodynamic conditions.

2.3. Temperature Polarization. In general, the main resistances are located at the boundary layer within the membrane and also on each side of the membrane.

Boundary layer resistance can be modeled by temperature polarization (TPC). The TPC $(\Theta)$ indicates heat transfer boundary layer resistances relative to the total heat transfer resistance

$$
\Theta=\frac{\Delta T}{\Delta T_{\max }}=\frac{\left(T_{f m}-T_{p m}\right)}{\left(T_{f b}-T_{p b}\right)} .
$$

Temperature polarization coefficient (TPC) often used as an indirect index of efficiency for the MD process, for most systems, the range of TPC falls between 0.4 and 0.8 and it is close to unity for a well designed system which means that the system fluid dynamics are in good conditions and the process is controlled by mass transfer within the membrane. Where for the value of TPC approaching zero for poorly designed systems, the process is limited by heat transfer through boundary layers $[6,14,15]$.

\section{Experimental Investigation}

3.1. Experimental Modules. The hydrophobic membrane module used in this work was 9 polymeric tubular membranes tubes arranged in a zigzag mode, with $2.8 \mathrm{~m}$ length and $0.013 \mathrm{~m}$ inner diameter. The total effective area of the module was $0.1144 \mathrm{~m}^{2}$. This polymeric membrane has $\mathrm{pH}$ ranged from 1.5 to 12 and maximum temperature and pressure of $80^{\circ} \mathrm{C}$ and 64 bar, respectively. Nitric acid (0.2\%) in distilled water can be used for cleaning this membrane at a temperature of $40^{\circ} \mathrm{C}$. The membrane had 0.72 micrometer pore size, $51 \%$ porosity, and $600 \mu \mathrm{m}$ thickness.

3.2. Experimental Apparatus. The experimental setup is shown schematically in Figure 2, whereas the schematic diagram of tubular membrane module is shown in Figure 3. The feed of pure water and brackish water is fed from a transparent feed tank to the tubular membrane module of area $0.1144 \mathrm{~m}^{2}$ by a small diaphragm pump. The pressure gauge was placed at the end of the membrane module for circulating the concentrated stream to the feed tank. The level of the feed is to be observed with time to evaluate the evaporation flux. The feed flow was measured using a Rosemount magnetic flow meter ranged from 60 to $240 \mathrm{~L} / \mathrm{h}$. Moreover, the feed is to be kept at constant feed temperatures $\left(40,50,60\right.$, and $\left.70^{\circ} \mathrm{C}\right)$ by using a heat exchanger connected to a controlled temperature water bath. The inlet and outlet temperatures were measured using two thermometers probe attached at both sides of the membrane modules. 


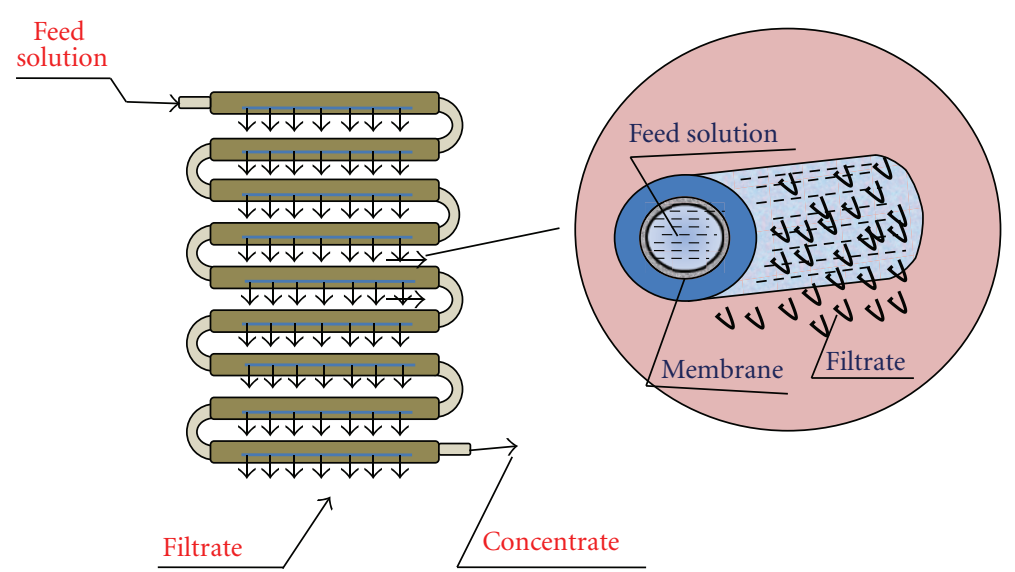

FIGURE 3: Schematic diagram of tubular membrane module.

3.3. Experimental Procedures. For preparing the feed solution, sodium chloride crystals, purchased from Chemical Company, were dissolved in distilled water to produce the required concentration. Brackish sodium chloride solutions were used as a standard saline solution for the investigations. The brackish sodium chloride concentration was measured by conductivity meter. When the experiments were running, the flux measured every 10 minutes, each run lasted for 3 hours. The evaporation flux for each experimental run was the mean value of the fluxes computed at steady state operation with experimental error less than $5 \%$.

\section{Results and Discussion}

Experiments were carried out using pure water and aqueous solution of sodium chloride $\mathrm{NaCl}$. The effect of operating parameters, namely, feed temperature, feed flow rate, and feed concentration on permeate flux was investigated in these experiments.

4.1. Pure and Saline Water. The first experiments were performed with pure water operated at different feed temperature, the feed bulk temperature values used were 40, 50, 60, and $70^{\circ} \mathrm{C}$. During the experiment, the level in the feed tank was observed and maintained by adding the retain amounts of feed water to the feed tank every $10 \mathrm{~min}$. The flux was calculated by plotting the cumulative volume versus time and taking the slope. As shown in Figure 4, the experimental flux values have been measured by varying the feed temperature from 40 to $70^{\circ} \mathrm{C}$ and feed water flow rate from 60 to $240 \mathrm{~L} / \mathrm{h}$.

4.2. Membrane Distillation Coefficient and Pure Water Flux. The vapor pressure difference $\Delta P_{v m}$ was calculated at the membrane surface temperatures $T_{f m}$ and $T_{p m}$, and plotted against the steady state fluxes obtained at selected feed temperatures as illustrated in Figure 5. On the basis of (1), it can be concluded that the slope of the straight line of the plot thus obtained gives the value of membrane distillation coefficient $\left(C_{m}=0.0004 \mathrm{~kg} / \mathrm{m}^{2} \mathrm{~h} \mathrm{~Pa}\right)$. The membrane distillation coefficient remains constant for a specific membrane

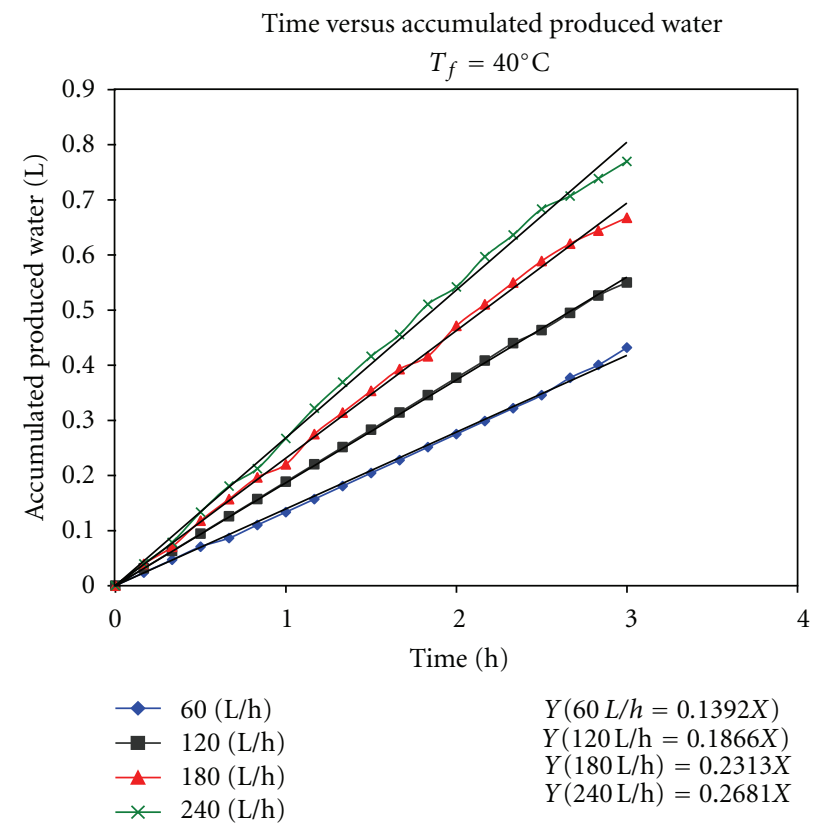

FIGURE 4: Accumulative produced water versus time at feed temperature $40^{\circ} \mathrm{C}$.

and vapor properties. Therefore, the membrane distillation coefficient $C_{m}$ obtained from pure water data can be used to predict the fluxes at different operating conditions.

4.3. Knudsen Number $\left(K_{n}\right)$. Knudsen number $K_{n}$ can be used as a first criteria for determining the predominant mechanism for water transport through tubular membrane module. $K_{n}$ is defined as the ratio of the mean free path $(\lambda)$ of diffusing molecules and the membrane pore diameter $\left(d_{p}\right)$ :

$$
K_{n}=\frac{\text { mean free path of water vapor }}{\text { membran pore size }} \Longrightarrow K_{n}=\frac{\lambda}{d_{p}} \text {. }
$$




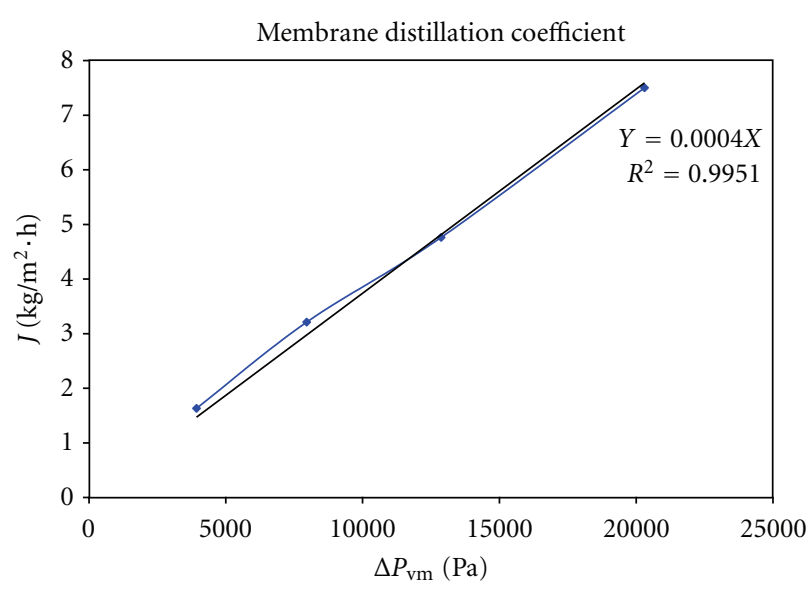

Figure 5: Water flux versus $\Delta P_{v m}$ at different feed temperatures, feed flow rate $120 \mathrm{~L} / \mathrm{h}$; permeate temperature $23^{\circ} \mathrm{C}$.

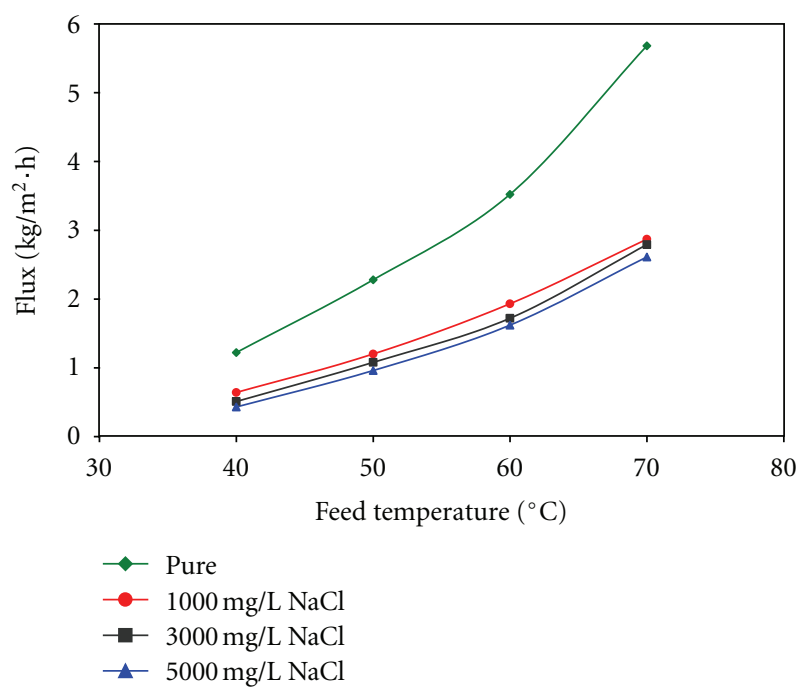

FIGURE 6: Effect of feed temperature on permeate flux at constant flow rate $60 \mathrm{~L} / \mathrm{h}$ and permeate temperature $23^{\circ} \mathrm{C}$.

According to kinetic theory of gases, the mean free path $(\lambda)$ can be calculated as follows [16]:

$$
\lambda=\frac{3 \mu_{v}}{P} \sqrt{\frac{\pi R T_{m}}{8 M_{w}}} .
$$

Since $K_{n}$ was equal to 0.12 , the Knudsen-Molecular transition diffusion mechanism regulates the mass transfer within the membrane pores [9].

4.4. Effect of Feed Temperature on Permeate Flux. Permeate flux is largely dependent on feed temperature. Fluxes of pure water and aqueous $\mathrm{NaCl}$ solution are represented in Figure 6. Increasing of feed temperature leads to increase in permeate flux as a consequence of rise in vapor pressure of gas-liquid interface on liquid feed side, which causes a simultaneous increase in the driving force of mass transfer.

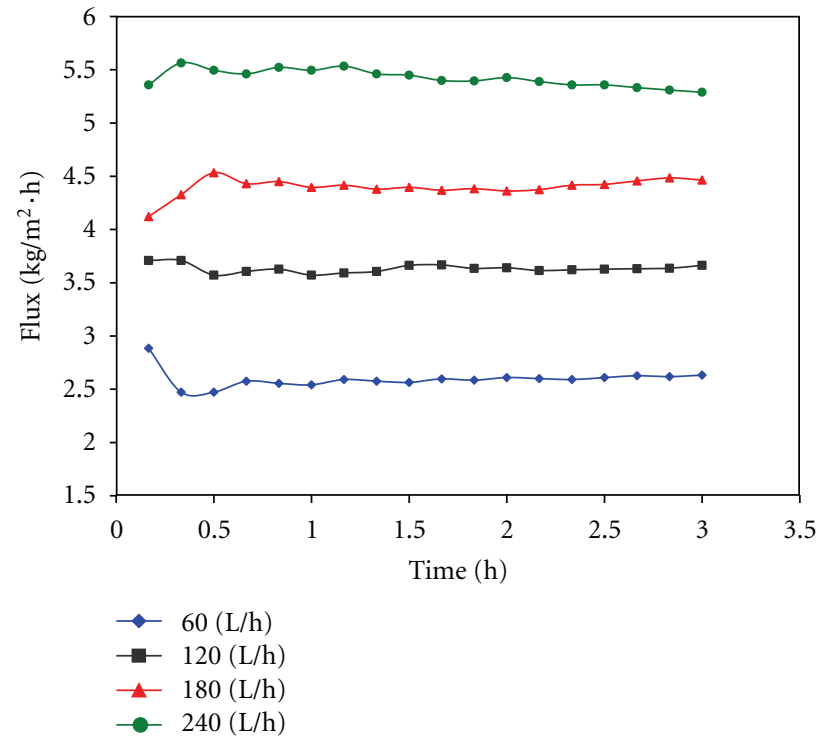

FIGURE 7: Effect of feed flow rate on permeate at feed temperature $70^{\circ} \mathrm{C}$ and $5000 \mathrm{mg} / \mathrm{L}$ of $\mathrm{NaCl}$ solution.

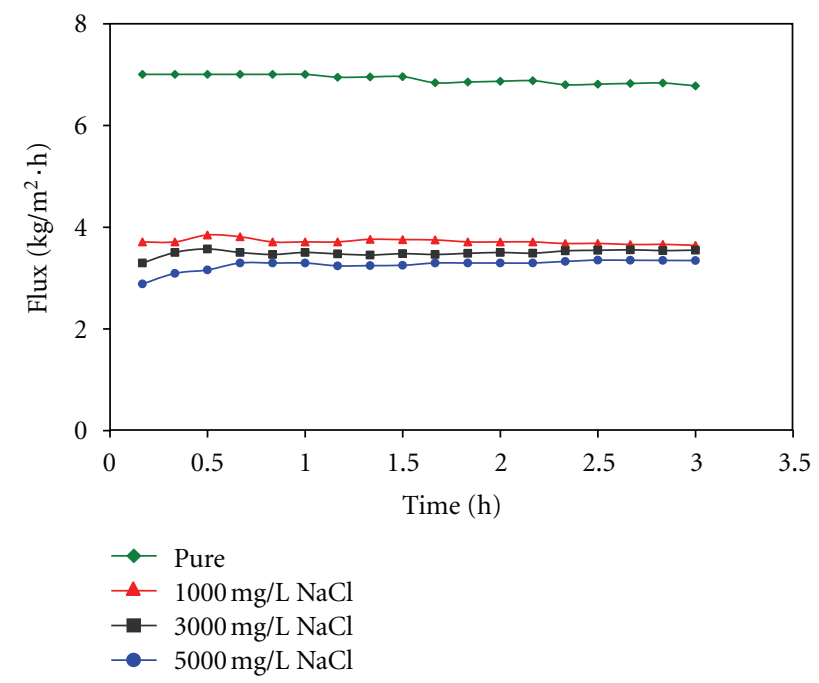

FIGURE 8: Effect of feed concentration on permeate at feed temperature $60^{\circ} \mathrm{C}$ and at feed flow rate $240 \mathrm{~L} / \mathrm{h}$.

4.5. Effect of Feed Flow Rate on Permeate Flux. At a constant temperature, the mass flux is dependent on feed flow rateS as depicted in Figure 7 showing the flux time curve at different feed flow rate at a constant temperature of $70^{\circ} \mathrm{C}$. The mass flux is directly proportional to feed flow rate since a rise in feed flow rate causes a rise in turbulence, reduction of heat transfer resistance in the boundary layers, and consequential rise in mass transfer coefficient. Moreover, the increase of feed boundary heat transfer coefficient $h_{f}$ with Reynolds number leadS to further rise in membrane surface temperature $T_{f m}$ and temperature polarization coefficients as depicted in Figure 8. As a result of higher feed surface temperature $T_{f m}$ and lower permeate surface temperature $T_{p m}$ leads to larger driving force resulting in an increasing 
TABLE 1: Heat transfer coefficients of the feed boundary layer.

\begin{tabular}{|c|c|c|c|c|c|}
\hline & \multirow{2}{*}{$T_{f}{ }^{\circ} \mathrm{C}$} & \multirow{2}{*}{ Pure water } & \multicolumn{3}{|c|}{ Aqueous $\mathrm{NaCl}, \mathrm{mg} / \mathrm{L}$} \\
\hline & & & 1000 & 3000 & 5000 \\
\hline \multirow{4}{*}{$\operatorname{Re}_{f}$} & 40 & 7,043 & 7,438 & 7,446 & 7,384 \\
\hline & 50 & 8,296 & 9,123 & 9,088 & 9,052 \\
\hline & 60 & 9,355 & 10,259 & 10,225 & 10,212 \\
\hline & 70 & 10,794 & 11,015 & 11,000 & 10,994 \\
\hline \multirow{4}{*}{$h_{f}$} & 40 & 15,810 & 9,171 & 8,714 & 8,120 \\
\hline & 50 & 16,768 & 9,867 & 9,459 & 8,853 \\
\hline & 60 & 17,501 & 10,295 & 9,944 & 9,328 \\
\hline & 70 & 18,405 & 10,605 & 10,283 & 9,648 \\
\hline
\end{tabular}

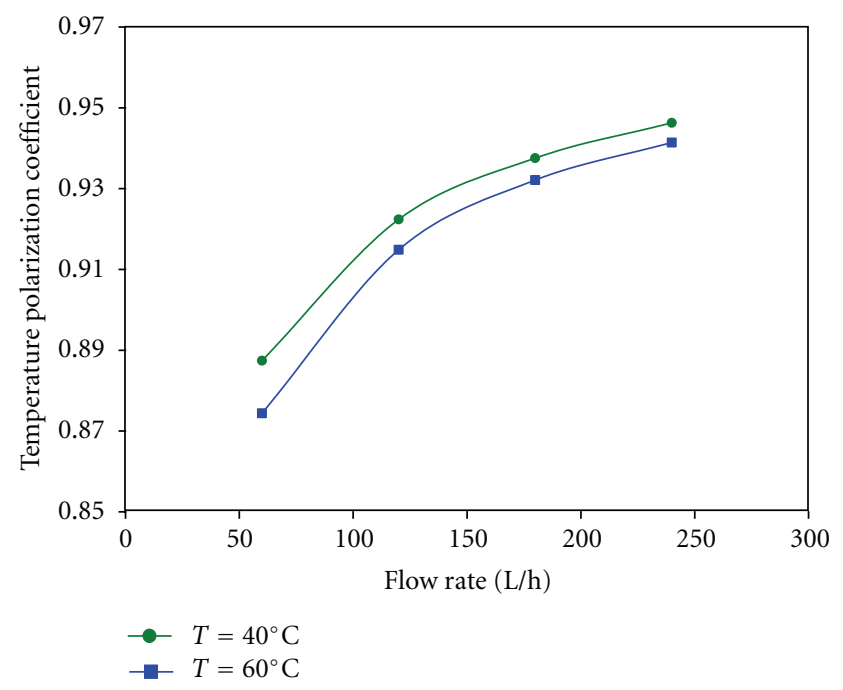

Figure 9: Temperature polarization coefficients versus feed flow rate at 40 and $60^{\circ} \mathrm{C}$ feed temperature and $5000 \mathrm{mg} / \mathrm{L}$.

in mass flux. Table 1 lists the examples of heat transfer coefficients.

4.6. Effect of Feed Concentration on Permeate Flux. Feed concentrations are another major factor which affects the permeate flux, where higher concentrations lead to lower permeate flux as shown in Figure 8. Vapor pressure is believed to play an important role of these changes in permeate flux. Decline in permeate flux has also been observed with time, the decrease being further accelerated by increasing feed concentrations. From Figure 9, the feed temperature and the concentrations of aqueous $\mathrm{NaCl}$ solution were seen to affect the temperature polarization and concentration polarization on the heat and mass transfer boundary layer thickness. A lowering of vapor pressure as a consequence of rise in concentration of aqueous $\mathrm{NaCl}$ solution leads to decline in the driving force across the membrane, thereby causing a lowering of permeate flux.

4.7. Heat Transfer Analysis. On the basis of Figure 9, the values of temperature polarization coefficients can be deduced to lie within the range of $0.89-0.94$ and $0.87-0.93$ at $40^{\circ} \mathrm{C}$ and $60^{\circ} \mathrm{C}$ feed temperature, respectively. These values are indicative of the suitability of the system design and also portray the fact that mass transfer across the membrane is a major determinant of the process. Increasing in TPC as a consequence of increased feed flow rate is due to lowering of heat transfer resistance within the boundary layer. This leads to an elevation of TPC, which results in increased driving force for mass transfer across the membrane. However, TPC decreased with increase in feed temperature as depicted in Figure 9, and there is an increase in mass flux. However, there is a simultaneous rise in heat flux invading the thermal boundary layer leading to exaggeration of temperature gradient as can be derived from (4) and (7).

Table 2 provides the calculations leading to determination of heat transfer components. Heat flux rises with feed temperatures and falls with feed concentration, which concurs with the above discussion. The resistance across the membrane is approximately 27-46 times larger than that for the feed stream. The loss of conduction across the membrane was $60-85 \%$, which indicated further loss with an increase in feed concentration, but fell with rise in feed temperatures.

\section{Conclusions}

The experimental flux values of distilled and synthetic salt water have been measured by varying feed temperatures, feed water flow rates, and feed concentration from 40 to $70^{\circ} \mathrm{C}, 60$ to $240(\mathrm{~L} / \mathrm{h})$, and 1000 to $5000 \mathrm{mg} / \mathrm{L}$, respectively. The fluxes of distilled and synthetic salt water are related to feed temperatures, feed flow rates, and feed concentrations. The vapor transport mechanism is controlled by Knudsen molecular diffusion transition mechanism depending on temperature, flow rate, and feed concentration. In the present analysis, it is obvious from the results that flux was increased with feed temperatures, feed flow rates and decreased with feed concentrations. The value of membrane distillation coefficient $C_{m}$ obtained from feed of pure water may be used for predicting the flux. Moreover, it was concluded that the membrane distillation coefficient $C_{m}$ depends greatly on the operating conditions. The temperature polarization coefficient has been demonstrated to rise with feed flow rate and fall with an increase in feed temperature. TPC values as high as $0.89-0.94$ were obtained indicating the efficiency of 
TABLE 2: Analysis of heat transfer of the system.

\begin{tabular}{|c|c|c|c|c|c|}
\hline \multirow{2}{*}{$T_{f}{ }^{\circ} \mathrm{C}$} & \multirow{2}{*}{ Heat flux, $\mathrm{W} / \mathrm{m}^{2} Q_{f}=Q_{p}=Q_{v}+Q_{c}$} & \multirow{2}{*}{$U W / \mathrm{m}^{2} \mathrm{~K}$} & \multirow{2}{*}{$\mathrm{Q}_{T}=U \Delta T_{f} \mathrm{~W} / \mathrm{m}^{2}$} & \multicolumn{2}{|c|}{ Heat transfer resistance, $\mathrm{m}^{2} \mathrm{~K} / \mathrm{W}$} \\
\hline & & & & $1 / h_{f}$ & {$\left[1 /\left(h_{m}+\left(J_{m} \Delta H_{v}\right) /\left(T_{f m}-T_{p m}\right)\right)\right]$} \\
\hline & \multicolumn{5}{|c|}{ Pure water } \\
\hline 40 & $5,257=1,363+3,894$ & 326.50 & 5,257 & $6.32 \times 10^{-5}$ & $2.93 \times 10^{-3}$ \\
\hline 50 & $8,766=2,713+6,053$ & 348.56 & 8,766 & $5.96 \times 10^{-5}$ & $2.75 \times 10^{-3}$ \\
\hline 60 & $11,715=3,955+7760$ & 362.12 & 11,715 & $5.71 \times 10^{-5}$ & $2.64 \times 10^{-3}$ \\
\hline \multirow[t]{2}{*}{70} & $16,260=6,327+9,933$ & 390.40 & 16,260 & $5.43 \times 10^{-5}$ & $2.45 \times 10^{-3}$ \\
\hline & \multicolumn{5}{|c|}{ Aqueous $\mathrm{NaCl}, 1000 \mathrm{mg} / \mathrm{L}$} \\
\hline 40 & $4,397=715+3,682$ & 282.76 & 4,397 & $1.09 \times 10^{-4}$ & $3.32 \times 10^{-3}$ \\
\hline 50 & $7,217=1,357+5,860$ & 291.01 & 7,217 & $1.01 \times 10^{-4}$ & $3.23 \times 10^{-3}$ \\
\hline 60 & $9,603=2,088+7,515$ & 301.03 & 9,603 & $9.71 \times 10^{-5}$ & $3.12 \times 10^{-3}$ \\
\hline \multirow[t]{2}{*}{70} & $13,028=3,418+9,610$ & 317.37 & 13,028 & $9.43 \times 10^{-5}$ & $2.96 \times 10^{-3}$ \\
\hline & \multicolumn{5}{|c|}{ Aqueous $\mathrm{NaCl}, 3000 \mathrm{mg} / \mathrm{L}$} \\
\hline 40 & $4,329=648+3,681$ & 277.50 & 4,329 & $1.14 \times 10^{-4}$ & $3.37 \times 10^{-3}$ \\
\hline 50 & $7,085=1,290+5,795$ & 288.01 & 7,085 & $1.06 \times 10^{-4}$ & $3.25 \times 10^{-3}$ \\
\hline 60 & $9,495=2,062+7,433$ & 299.99 & 9,495 & $1.01 \times 10^{-4}$ & $3.12 \times 10^{-3}$ \\
\hline \multirow[t]{2}{*}{70} & $12,801=3,345+9,456$ & 316.08 & 12,801 & $9.72 \times 10^{-4}$ & $2.96 \times 10^{-3}$ \\
\hline & \multicolumn{5}{|c|}{ Aqueous $\mathrm{NaCl}, 5000 \mathrm{mg} / \mathrm{L}$} \\
\hline 40 & $4,142=560+3,582$ & 271.60 & 4,142 & $1.23 \times 10^{-4}$ & $3.42 \times 10^{-3}$ \\
\hline 50 & $6,949=1,230+5,719$ & 284.78 & 6,949 & $1.13 \times 10^{-4}$ & $3.27 \times 10^{-3}$ \\
\hline 60 & $9,273=1,894+7,378$ & 293.90 & 9,273 & $1.07 \times 10^{-4}$ & $3.17 \times 10^{-3}$ \\
\hline 70 & $12,330=2,952+9,377$ & 305.94 & 12,330 & $1.04 \times 10^{-4}$ & $3.05 \times 10^{-3}$ \\
\hline
\end{tabular}

system with respect to heat transfer. The heat transfer of the system is controlled by the heat transfer in the membrane where the membrane resistance is $27-46$ times higher than that of feed stream.

\section{Nomenclature}

$C_{f b}$ : Molar concentration at feed bulk

$C_{f m}$ : Molar concentration at membrane surface

$C_{m}$ : Mass transfer coefficient $\left(\mathrm{kg} / \mathrm{m}^{2} \mathrm{~h} \mathrm{~Pa}\right)$

$M_{w}$ : Molecular weight of water $(\mathrm{kg} / \mathrm{kmol})$

$d_{p}: \quad$ Pore size diameter of the membrane $(\mu \mathrm{m})$

$\Delta H_{\nu}$ : Water vapor latent heat of vaporization $(\mathrm{kJ} / \mathrm{kg})$

$h_{f}$ : Heat transfer coefficient at the feed side $\left(\mathrm{W} / \mathrm{m}^{2} \mathrm{~K}\right)$

$h_{m}$ : Heat transfer coefficient of the membrane $\left(\mathrm{W} / \mathrm{m}^{2} \mathrm{~K}\right)$

$h_{p}$ : Heat transfer coefficient at the permeate side $\left(\mathrm{W} / \mathrm{m}^{2} \mathrm{~K}\right)$

$J_{m}: \quad$ Mass vapor flux $\left(\mathrm{kg} / \mathrm{m}^{2} \mathrm{~h}\right)$

$k_{f}$ : Mass transfer coefficient $(\mathrm{m} / \mathrm{s})$

$k_{g}$ : Thermal conductivity of vapor fills the membrane pores $(\mathrm{W} / \mathrm{m} \mathrm{K})$

$k_{m}$ : Average thermal conductivity of membrane and vapor $(\mathrm{W} / \mathrm{m} \mathrm{K})$

$k_{s}: \quad$ Thermal conductivity of the membrane (W/m K)

$P: \quad$ Total pressure $(\mathrm{Pa})$

$P_{v m 1}$ : Water vapor pressure at the feed membrane surface $(\mathrm{Pa})$
$P_{v m 2}$ : Water vapor pressure at the permeate surface $(\mathrm{Pa})$

$\Delta P_{v m}$ : Vapor pressure difference at membrane sides $(\mathrm{Pa})$

$Q_{c}$ : Heat flux by conduction (W/m2)

$Q_{f}:$ Heat flux from the feed bulk to the vapor-liquid interface $\left(\mathrm{W} / \mathrm{m}^{2}\right)$

$Q_{p}$ : Heat flux from the vapor-liquid interface to the permeate side $\left(\mathrm{W} / \mathrm{m}^{2}\right)$

$Q_{T}:$ Total heat flux $\left(\mathrm{W} / \mathrm{m}^{2}\right)$

$Q_{v}$ : Heat flux by vaporization $\left(\mathrm{W} / \mathrm{m}^{2}\right)$

$R: \quad$ Universal gas constant $\left(\mathrm{m}^{3} \mathrm{~Pa} / \mathrm{mol} \mathrm{K}\right)$

$R_{f}$ : Resistance at feed boundary layer $\left(\mathrm{Pa} \mathrm{m}{ }^{2} \mathrm{~h} / \mathrm{kg}\right)$

$R_{m}$ : $\quad$ Resistance at membrane surface $\left(\mathrm{Pa} \mathrm{m}{ }^{2} \mathrm{~h} / \mathrm{kg}\right)$

$R_{p}: \quad$ Resistance at permeate boundary layer $\left(\mathrm{Pa} \mathrm{m}{ }^{2} \mathrm{~h} / \mathrm{kg}\right)$

$T_{m}$ : $\quad$ Mean temperature $\left({ }^{\circ} \mathrm{C}, \mathrm{K}\right)$

$T_{f}: \quad$ Water feed temperature $\left({ }^{\circ} \mathrm{C}, \mathrm{K}\right)$

$T_{f b}$ : Temperature at the feed bulk side $\left({ }^{\circ} \mathrm{C}\right.$, K)

$T_{p b}: \quad$ Temperature at the permeate bulk side $\left({ }^{\circ} \mathrm{C}, \mathrm{K}\right)$

$T_{f m}: \quad$ Temperature at the feed membrane surface $\left({ }^{\circ} \mathrm{C}, \mathrm{K}\right)$ 
$T_{p m}$ : Temperature at the bulk membrane surface $\left({ }^{\circ} \mathrm{C}, \mathrm{K}\right)$

$\Delta T_{b}$ : Bulk temperature difference for feed and permeate sides $\left({ }^{\circ} \mathrm{C}, \mathrm{K}\right)$

$U$ : Overall heat transfer coefficient $\left(\mathrm{W} / \mathrm{m}^{2} \mathrm{~K}\right)$.

\section{Dimensionless Numbers}

$K_{n}$ : Knudsen number

Re: Reynolds number

Sc: Schmidt number

Sh: Sherwood number

$\Theta$ : Temperature polarization coefficient (TPC).

\section{Greek Letters}

$\delta_{m}:$ Membrane thickness $(\mathrm{m})$

$\varepsilon$ : Membrane porosity

$\lambda$ : Mean free path $(\mathrm{m})$.

\section{Subscripts}

b: Bulk

Exp.: Experimental

$f: \quad$ Feed

$m$ : Membrane

MD: Membrane distillation

$s: \quad$ Salt

Theor.: Theoretical

w: Water

1: $\quad$ Membrane location at feed side

2: $\quad$ Membrane location at permeate side.

\section{Acknowledgment}

The authors wish to express their sincere thanks to the Public Authority of Applied Education (PAAET) in Kuwait for funding this research.

\section{References}

[1] L. P. Bhausaheb, B. P. Saroj, M. A. Rajendra, and G. Mahendra, "The heat and mass transfer phenomena in vacuum membrane distillation for desalination," International Journal of Chemical and Biomolecular Engineering, vol. 3, pp. 33-38, 2010.

[2] J. I. Mengual, M. Khayet, and M. P. Godino, "Heat and mass transfer in vacuum membrane distillation," International Journal of Heat and Mass Transfer, vol. 47, no. 4, pp. 865-875, 2004.

[3] S. Al-Obaidani, E. Curcio, F. Macedonio, G. Di Profio, H. AlHinai, and E. Drioli, "Potential of membrane distillation in seawater desalination: thermal efficiency, sensitivity study and cost estimation," Journal of Membrane Science, vol. 323, no. 1, pp. 85-98, 2008.
[4] M. S. El-Bourawi, Z. Ding, R. Ma, and M. Khayet, "A framework for better understanding membrane distillation separation process," Journal of Membrane Science, vol. 285, no. 1-2, pp. 4-29, 2006.

[5] A. Burgoyne and M. M. Vahdati, "Permeate flux modeling of membrane distillation," Filtration and Separation, vol. 36, no. 1, pp. 49-53, 1999.

[6] K. W. Lawson and D. R. Lloyd, "Membrane distillation," Journal of Membrane Science, vol. 124, no. 1, pp. 1-25, 1997.

[7] L. Martinez-Diez and M. I. Vasquez-Gonsalez, "Effects of polarization on mass transport through hydrophobic porous membranes," Industrial \& Engineering Chemistry Research Journal, vol. 37, pp. 4128-4135, 1998.

[8] E. Curcio and E. Drioli, "Membrane distillation and related operations-a review," Separation and Purification Reviews, vol. 34, no. 1, pp. 35-86, 2005.

[9] L. Zhigang, C. Biaohua, and D. Zhongwei, Membrane Distillation, Special Distillation Processes, Elsevier Science, Amsterdam, The Netherlands, 2005.

[10] S. Srisurichan, R. Jiraratananon, and A. G. Fane, "Mass transfer mechanisms and transport resistances in direct contact membrane distillation process," Journal of Membrane Science, vol. 277, no. 1-2, pp. 186-194, 2006.

[11] V. Soni, J. Abildskov, G. Jonsson, and R. Gani, "A general model for membrane-based separation processes," Computers and Chemical Engineering, vol. 33, no. 3, pp. 644-659, 2009.

[12] T. C. Chen and C. D. Ho, "Immediate assisted solar direct contact membrane distillation in saline water desalination," Journal of Membrane Science, vol. 358, no. 1-2, pp. 122-130, 2010.

[13] R. Thanedgunbaworn, R. Jiraratananon, and M. H. Nguyen, "Vapour transport mechanism in osmotic distillation process," International Journal of Food Engineering, vol. 5, no. 5, article 3, pp. 1-9, 2009.

[14] A. G. Fane, R. W. Schofield, and C. J. D. Fell, "The Efficient Use of Energy in Membrane Distillation," Desalination, vol. 64, pp. 231-243, 1987.

[15] S. Bandini, C. Gostoli, and G. C. Sarti, "Separation efficiency in vacuum membrane distillation," Journal of Membrane Science, vol. 73, no. 2-3, pp. 217-229, 1992.

[16] C. Geankoplis, Transport Processes and Unit Operations, Prentice-Hall, Englewood Cliffs, NJ, USA, 3rd edition, 1993. 

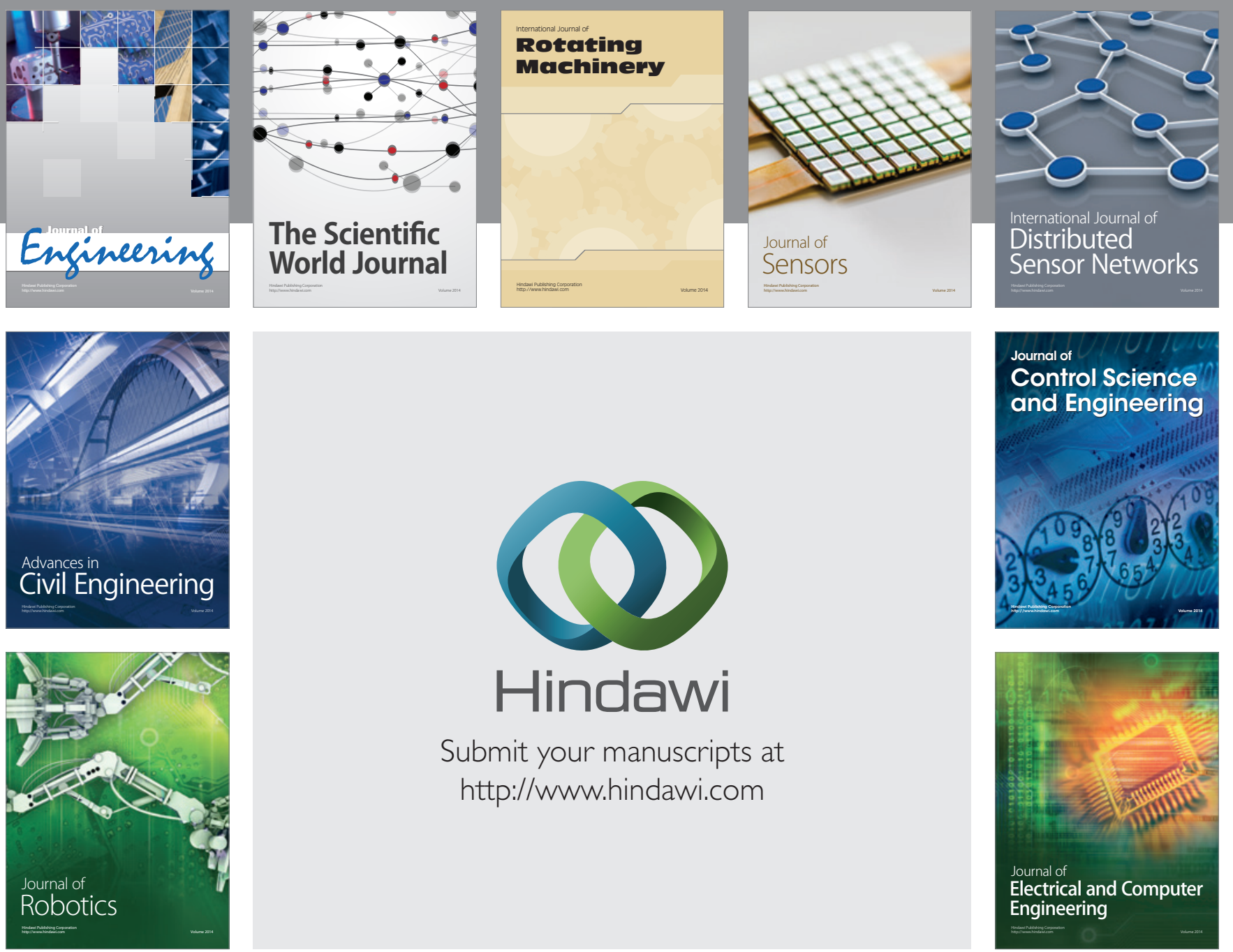

Submit your manuscripts at

http://www.hindawi.com
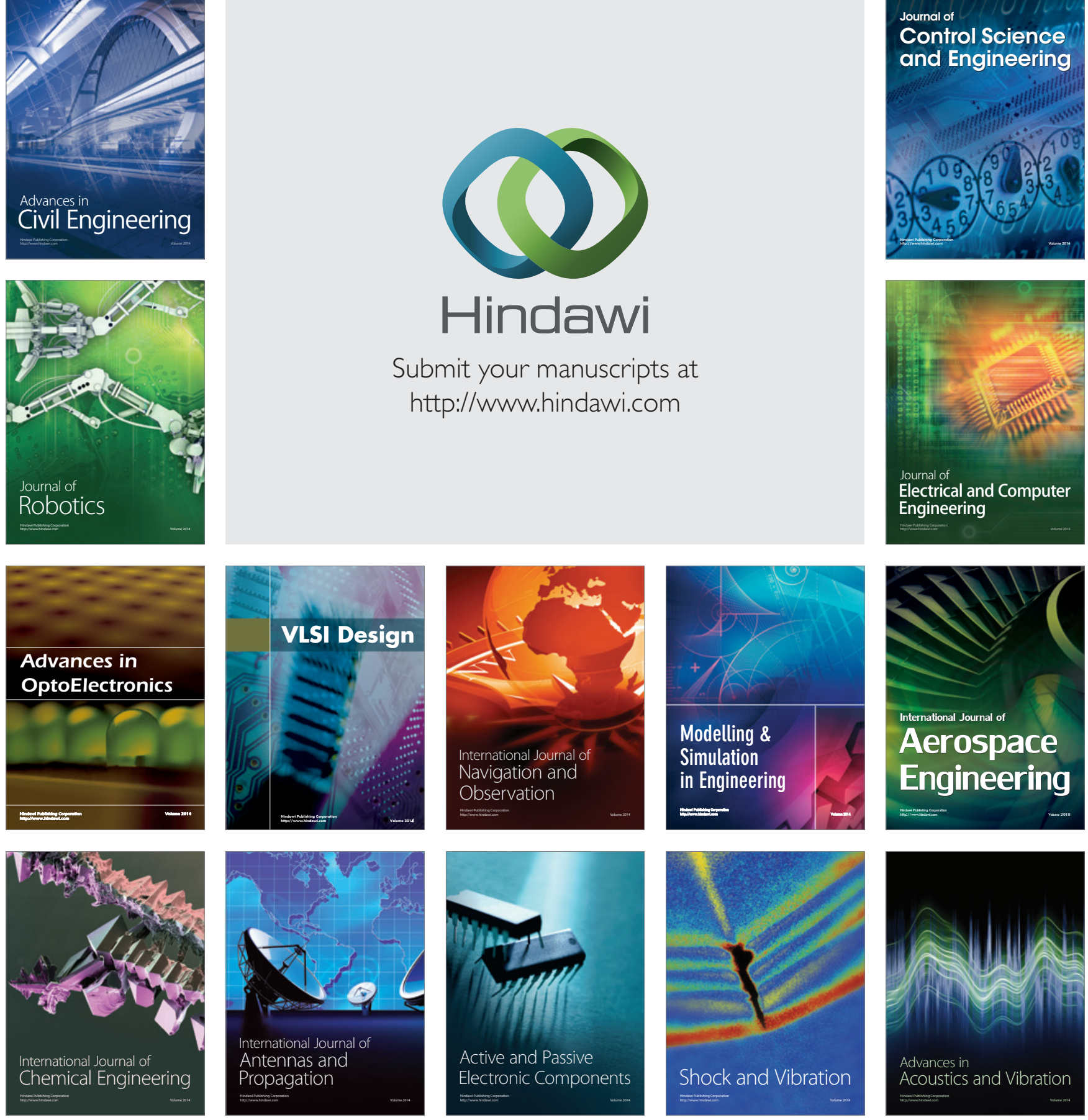